\title{
Wear Behaviour of Nanostructured Polymer-Based Safety Films on Soda-Lime Glass
}

\author{
C. N. Panagopoulos ${ }^{1, *}$, E. P. Georgiou ${ }^{2,3}$, G. S. $\operatorname{Tradas}^{1}$ and K. I. Giannakopoulos ${ }^{1}$ \\ 1 Laboratory of Physical Metallurgy, National Technical University of Athens, Zografos, 15780 Athens, Greece; \\ geotra5@yahoo.gr (G.S.T.); kgiannak1@yahoo.gr (K.I.G.) \\ 2 Department of Materials Engineering (MTM), Katholieke Universiteit Leuven (K.U. Leuven), \\ Kasteelpark Arenberg 44, B-3001 Leuven, Belgium; emmanuel.georgiou@mtm.kuleuven.be \\ 3 Falex Tribology NV, Wingepark 23B, 3110 Rotselaar, Belgium \\ * Correspondence: chpanag@metal.ntua.gr; Tel.: +30-210-7722171
}

Academic Editor: Philippe Dubois

Received: 27 May 2016; Accepted: 23 June 2016; Published: 8 July 2016

\begin{abstract}
The wear behaviour of bare and polymer-coated soda-lime glass specimens sliding against 440C stainless steel counterfaces was investigated with the aid of a pin-on-disk apparatus. The selected polymeric coatings were commercially supplied safety films, which are nowadays extensively applied on glass in the automotive and construction industry. One of their main failures is the degradation of their properties due to wear. In this work, the frictional behaviour of these coatings on glass were evaluated and compared to those of bare soda-lime glass. Correlations have been also made between the worn surfaces and weight loss in order to investigate the effect of wear conditions (speed, load) on the wear behaviour of these tribosystems. In addition, during the dry wear of soda-lime glass sliding against stainless steel counterfaces, the dominant wear mechanisms were found to be localized adhesion and abrasion, whereas, in the case of the multilayered polymeric coatings localized adhesion, deformation and tearing were observed.
\end{abstract}

Keywords: glass; multilayered polymeric coatings; safety films; wear; adhesion

\section{Introduction}

Ceramic materials, because of their excellent technological properties, such as strength, hardness, chemical inertness, and thermal shock resistance, have been used in many technological fields and manufacturing applications. In particular, the various glasses are promising for use in industrial and technological areas [1-4]. However, several aspects need to be addressed before they can be applied to even more fields of application. One of these aspects is their tribological properties, as most glasses are found to have relatively low resistance to wear $[5,6]$ due to their considerably low fracture toughness $[7,8]$.

In particular, it has been found [9-12] that the abrasive resistance of glasses strongly depend on the wear conditions (applied load, sliding speed, countermaterial composition, etc.), which determine the occurring wear mechanisms. In particular, during the abrasive wear of soda-lime and borosilicate glass, abrasive debris particles form and agglomerate at the contacting interface $[9,10]$. Chemical analysis of these particles showed that they consisted of both tribomaterials (glass and metallic countermaterial). This is an indication that, apart from the abrasive mechanisms, adhesion phenomena can also occur in such a tribosystem. In addition, the wear mechanisms of soda-lime glass were also observed to depend on the nature of the counterface material [11,12]. Stiff metallic and ceramic counterfaces result in chipping and fracture of the glass by three-body abrasion, whereas polymeric counterfaces result in a ductile cutting of the glass, by a two-body abrasion mechanism. Recently [13], it was also reported that the tribological properties of soda-lime glass are very sensitive to environmental conditions. For 
example, in humid conditions, the counter-materials that were harder than the soda-lime glass were mainly damaged, indicating that the Archard relationship in not applicable under such conditions [13].

Despite the fact that satisfactory information on the tribological properties of glass is available [9-16], very little is actually known on the wear behaviour of glass with polymeric films. It should be noted that, during the last decade, polymer coatings adhering to glass are extensively used in the construction and automotive industries. The purpose of using such coatings is to reduce the amount of heat entering through the glass surfaces, to reduce direct and intense solar radiation, to decrease damage brought about by ultraviolet (UV) rays, to improve the aesthetics of buildings and cars, and to reduce the visibility of interior content, sites, and products through transparent glass. However, the above characteristics of these coatings can be significantly degraded by wear phenomena on their surface, which in certain cases can result in the loss of optical clarity or even wear through and detachment of the polymeric film.

Therefore, this research investigation focuses on the thorough study of the dry wear behaviour of multilayered polymer-based coatings on soda-lime glass, sliding against a 440C martensitic stainless steel counterface. The main reason for selecting a stainless steel counterface is because, in many industrial and technological applications, polymeric coated glasses are in direct contact with metallic materials (e.g., metallic frames). In addition, it has been reported $[17,18]$ that intense adhesion and abrasion phenomena can occur in tribosystems that consist of polymeric and metallic materials. For comparative reasons, the wear behaviour of bare soda-lime glass specimens was evaluated, using a wide range of experimental conditions.

\section{Materials and Methods}

The glass specimens used in this study were made from soda-lime glass with the following chemical composition (wt \%): $13.7 \% \mathrm{Na}_{2} \mathrm{O}, 9.54 \% \mathrm{CaO}, 4.43 \% \mathrm{MgO}, 0.869 \% \mathrm{Al}_{2} \mathrm{O}_{3}, 0.192 \% \mathrm{SO}_{3}, 0.178 \%$ $\mathrm{K}_{2} \mathrm{O}, 0.162 \% \mathrm{Fe}_{2} \mathrm{O}_{3}, \mathrm{SiO}_{2}$ balance, as found by XRF analysis. The specimens for wear measurements were paralelliped, with the dimensions $10 \mathrm{~cm} \times 10 \mathrm{~cm} \times 0.4 \mathrm{~cm}$. After manufacturing, a stress relief procedure was performed by annealing the produced soda-lime glass specimens for $2 \mathrm{~h}$ at $150{ }^{\circ} \mathrm{C}$, in an Ar inert automatic furnace, slowly cooling down to room temperature.

In the first series of coated soda-lime glass specimens, multilayered polymeric membranes (safety films) consisting of a thin layer of special acrylic adhesive, were adhered on the surface of the glass samples using a water and soap solution (just like in the actual application). Then, they were left to dry for 20 days at $18{ }^{\circ} \mathrm{C}$ (in dry conditions). These polymeric coatings were commercial safety films supplied by the 3M Company (Athens, Greece), and their trade name was SH4 20 SIARL. The thickness of these multilayered coatings was approximately $100 \mu \mathrm{m}$, and they consisted of polyester-based layers, and a thin metal-based scratch resistant hard coating as an outer layer. In the second series of coated soda-lime glass specimens, a different type of safety film was adhered. The second coating was also supplied by the 3M Company (Athens, Greece), and its trade name is ULTRA 600. The thickness of this multilayered coating was approximately $152 \mu \mathrm{m}$, and it consisted of about 40 polyester-based microlayers, which also had a similar thin metal-based scratch resistant hard coating as an outer layer. More detailed information on the structure and composition coatings cannot be given due to confidentiality issues.

A pin-on-disk wear apparatus was used for the sliding wear experiments. The multilayered polymer-coated and soda-lime glass specimens slid against a stationary counter pin of $440 \mathrm{C}$ martensitic stainless steel. The diameter of the pins was $5.5 \mathrm{~mm}$, and their hardness was $700 \mathrm{HVN}$. The surface roughness of the pins was found to be approximately $0.1 \mu \mathrm{m}$. Before each wear experiment, roughness measurements were conducted with the aid of a Marr Perthen Profilometer, in order to ensure that all the specimens had similar surface topography. The cut-off length of the roughness measurements was $0.8 \mathrm{~mm}$. The average surface roughness $\left(R_{\mathrm{a}}\right)$ of the multilayered polymer-coated soda-lime glass specimens was found to be approximately 0.02 and $0.01 \mu \mathrm{m}$, respectively. 
For the sliding wear experiments, 15,30,60, and $90 \mathrm{~cm} / \mathrm{s}$ sliding speeds were used and 2, 5, 10, and $20 \mathrm{~N}$ applied loads were selected, respectively. The sliding distance was always $500 \mathrm{~m}$. All wear experiments were performed at $20-25^{\circ} \mathrm{C}$ and $40 \%-45 \%$ humidity. With the aid of a PC, the friction coefficient was continuously monitored during the wear experiments. Before and after each wear test, the weight of coated and bare soda-lime glass specimens was measured on an electrobalance, with an accuracy of $\pm 0.1 \mathrm{mg}$. The wear tracks and the counterface pins were observed with the aid of a Zeiss Metallurgical Microscope. The crystallographic structure of the coating was investigated using a Siemens D $5000 \mathrm{X}$-ray diffractometer (XRD) with $\mathrm{Cu} \mathrm{K} \alpha$ radiation and a graphite monochromator. The adhesion strength between the safety films and the soda-lime glass substrate was studied with the aid of a Revetest scratch testing technique. The scratch tester was equipped with a Rockwell C conical diamond indenter with a tip angle of 1208 and a tip radius of $200 \mathrm{~mm}$. During the tests, an acoustic emission detector recorded the signals from the specimens. All scratch tests were conducted under increasing load, with a load rate of $10 \mathrm{~N} / \mathrm{mm}$.

It should be noted that each experiment was performed five times, and the mean values are given in the graphs presented below. However, taking into account the experimental errors, error bars are added in the graphs.

\section{Results \& Discussion}

Structural characterisation of the soda-lime glass substrate and multilayered polymer-coated specimens, by means of X-ray diffraction, is presented in Figure 1. The X-ray diffraction pattern of soda-lime glass is indicative of an amorphous material, as the width of the main peak appears broadened ( $2 \theta$ approximately from $15^{\circ}$ to $30^{\circ}$ ). However, X-ray diffraction study of the multilayered polymer-based coatings revealed that they were nanostructured, as a decrease of the width of their main peak along with an increase in peak intensity was observed. With the use of Debye-Scherrer's equation [19], the grain size of SH4 20 SIARL and ULTRA 600 safety films was estimated at approximately $4 \mathrm{~nm}$. Further analysis on the chemical composition and structure of these polymeric coatings could not be given without the 3M Company approval.

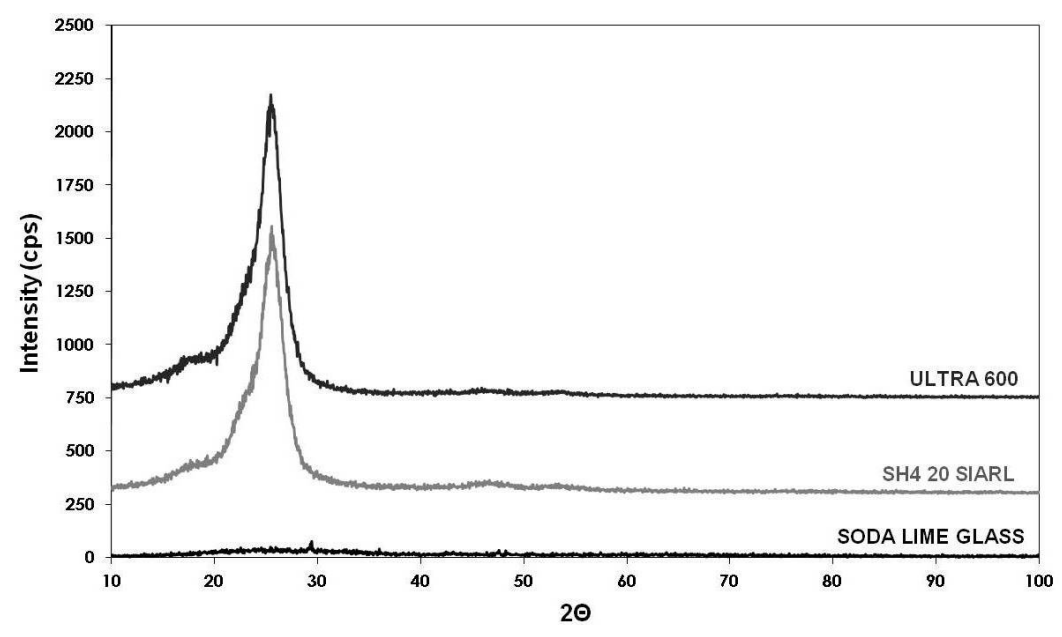

Figure 1. X-ray diffraction (XRD) pattern of multilayered polymer-based coatings on glass and bare soda-lime glass.

In Figure 2, the coefficient of friction as a function of sliding distance, for the tribosystems multilayered polymer coatings versus stainless steel and bare soda-lime glass versus stainless steel, under dry conditions, is presented. It should be noted that the graphs in Figure 2 were obtained for the same values of sliding speed and applied load $(30 \mathrm{~cm} / \mathrm{s}, 5 \mathrm{~N})$. From this figure, it can be clearly seen that the use of these nanostructured polymer-based coatings resulted in significant improvement of the frictional properties of the tribosystem. This observation could be attributed to the low flow stress 
of the polymeric layers [20], which leads to an easier capping or clogging of the contacting materials. Another factor that should be taken into consideration is that, during the sliding of soda-lime glass against stainless steel, chipping of glass particles at the interface of the contacting materials might occur. The formation of such particles has been observed to lead to three-body abrasion phenomena, which can have a strong influence on the coefficient of friction of the tribosystem. It is believed that the use of such multilayered polymeric coatings helps to maintain the cohesion of the brittle glass substrate and to prevent the detachment of particles that could cause three-body abrasion. This factor is considered extremely important for safety reasons for enhanced protection during the breaking of glass.

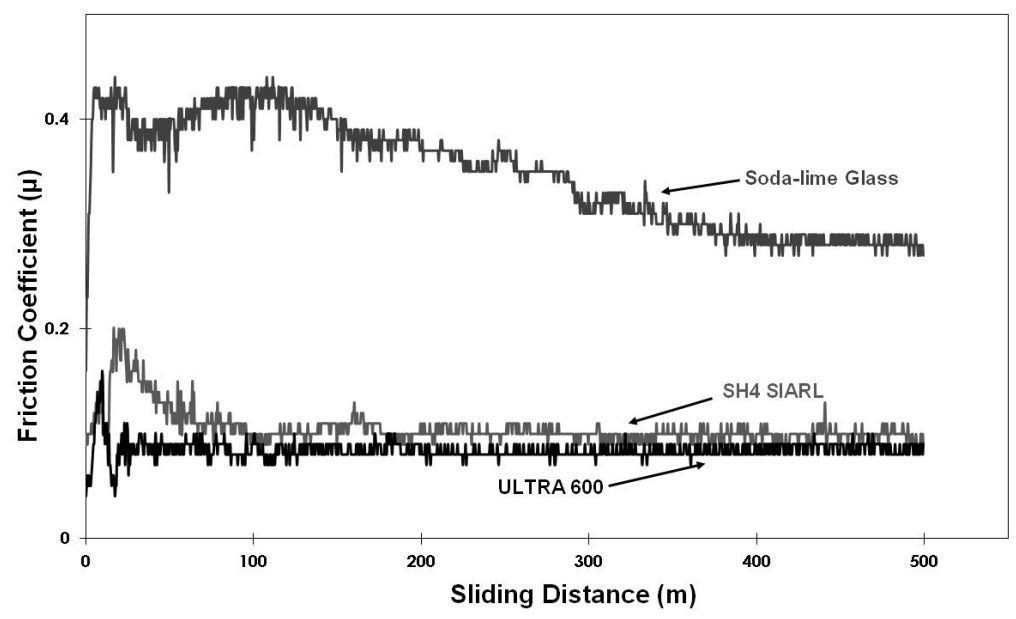

Figure 2. Friction coefficient vs. sliding speed for the tribosystem: (a) bare soda-lime glass-stainless steel; (b) SH4 SIARL coating-stainless steel; and (c) ULTRA 600 coating-stainless steel.

By comparing the two multilayered polymeric coatings, Ultra 600 coating seemed to be more effective for the selected conditions, as its coefficient of friction against stainless steel was found to be approximately 0.1 . However, in both coatings, high values of friction coefficient were observed during the first $50 \mathrm{~m}$. This observation could be possibly attributed to the existence of adhesion phenomena between the metal-based outer layer, the polymeric layers, or both and the metallic counterface $[17,18]$.

Figure 3 shows the friction coefficient as a function of applied load, for the multilayered polymeric coatings on glass and bare soda-lime glass specimens against stainless steel, under dry conditions. The sliding speed was held constant at $30 \mathrm{~cm} / \mathrm{s}$. The increase in applied load resulted in a decrease in the friction coefficient of the examined materials. It should be noted that the effect of applied load was more significant for the soda-lime glass, as the friction coefficient dropped from 0.7 to 0.4 . This observation could be partially attributed to the fact that the increase of the applied load may have caused strain hardening of the surface layers of the stainless steel counterface. Thus, according to Khruschov's theory [21], the hardening of the surfaces of sliding materials, leads to the higher wear resistance and to a lower coefficient of friction of the tribosystem. In addition, chipping and fracture of the glass by three-body abrasion should be taken into consideration. The formation of wear debris on the interface of the two antagonistic materials changes the "true" contacting area and thus might considerably affect the obtained friction coefficient values of the tribosystem. However, contrary to effect of applied load, the coefficient of friction of these tribosystems was found to be independent of the sliding speeds examined (Figure 4). 


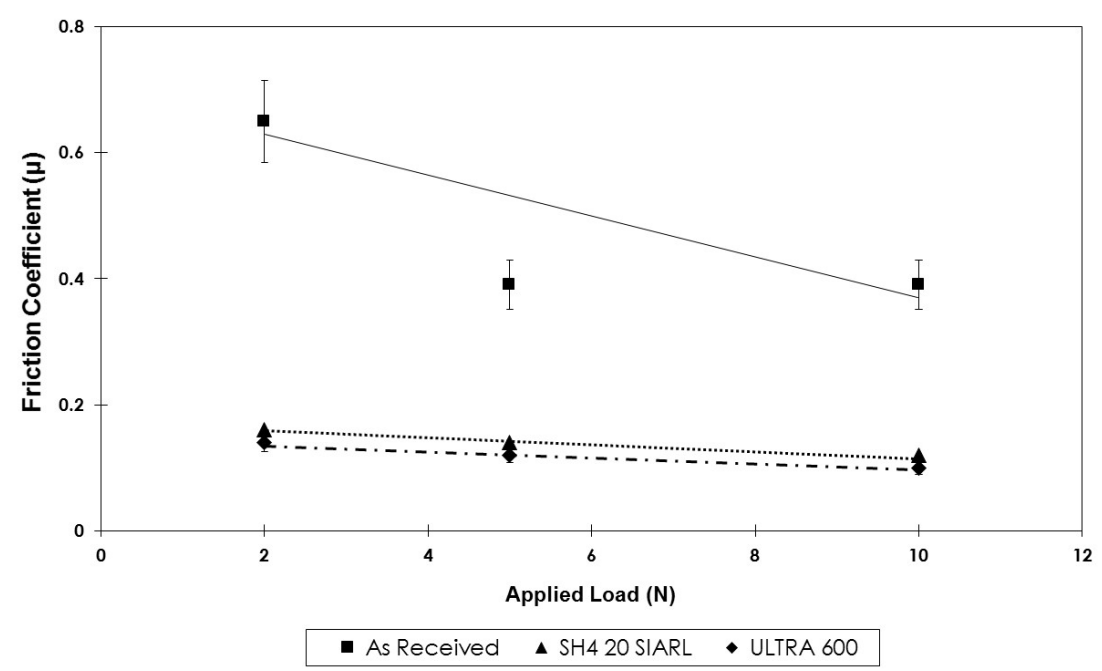

Figure 3. Effect of applied load on the friction coefficient of multilayered polymer coatings and bare soda-lime glass sliding against stainless steel.

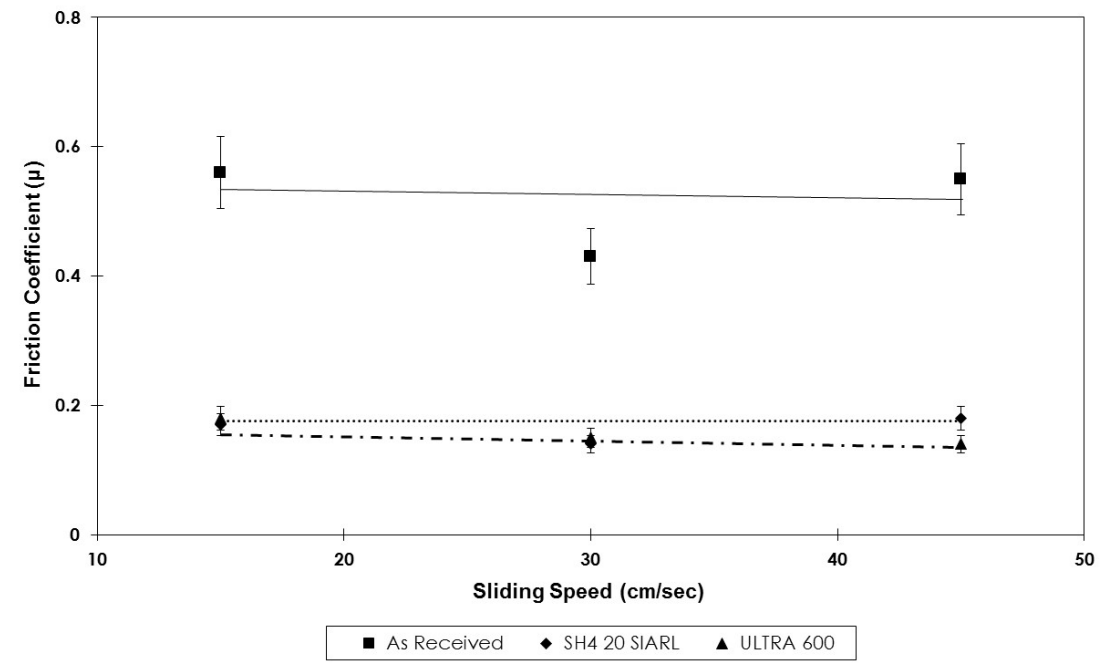

Figure 4. Effect of sliding speed on the friction coefficient of multilayered polymeric coatings and bare soda-lime glass against stainless steel

Figure 5 shows the variation in weight loss with the applied load for the polymer coatings on glass and soda-lime glass specimens after sliding for $500 \mathrm{~m}$. The sliding speed was $30 \mathrm{~cm} / \mathrm{s}$. The wear loss of the multilayered polymer coatings on glass and bare soda-lime glass was found to strongly depend on the applied load. In particular, for lower applied loads $(2-5 \mathrm{~N})$, the bare soda-lime glass specimens exhibited better wear resistance, possibly due to their higher surface hardness ( $588 \mathrm{HVN})$, in comparison to the soft polymeric coatings. However, at higher loads, due to the considerably low fracture toughness of glass [7,8], cracking and chipping of glass particles led to higher weight losses of bare soda-lime glass.

In addition, the weight loss of the examined specimens was also found to be proportional to the applied load. The above results are in complete agreement with Archard's law [22] concerning the wear of materials. 


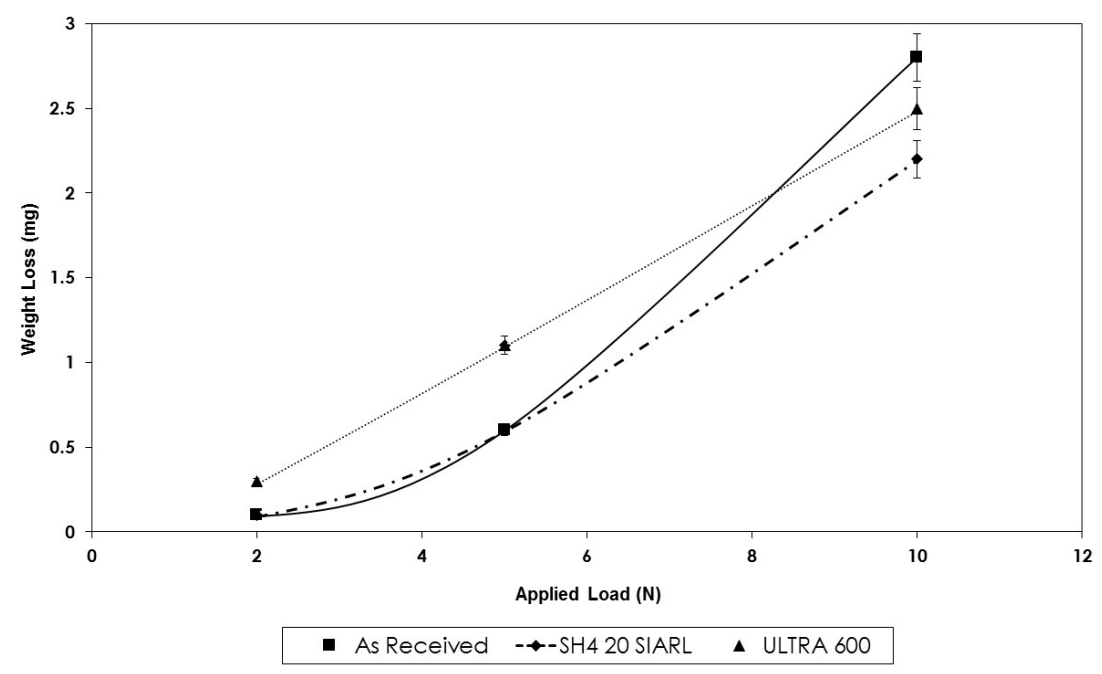

Figure 5. Effect of applied load on the weight loss of multilayered polymer-based coatings on glass and bare soda-lime glass.

Following the pin-on-disk wear experiments, metallographic studies of both the wear tracks and stainless steel pins, took place with the aid of the metallurgical microscope. In Figure 6a, an interior area of a typical wear scar of soda-lime glass specimen is presented. The dominant wear mechanism was severe abrasion, which led to the micro-cracking and ploughing of the surface layers of the soda-lime glass. However, the presence of micro-particles on the surface of the wear track and the pin (Figure 6a,b) implies the coexistence of an adhesion mechanism, mainly in the initial steps of the wear experiment [23]. As the wear conditions (e.g., applied load and sliding speed) became more intense, the abrasion and adhesion phenomena became more intense (Figure 6c). In addition, micro-cracks were also observed on the surface of $440 \mathrm{C}$ martensitic stainless steel countermaterial, possibly due to fatigue [24] (Figure 6b).

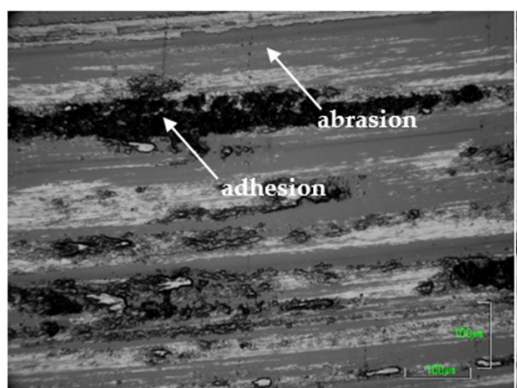

(a)

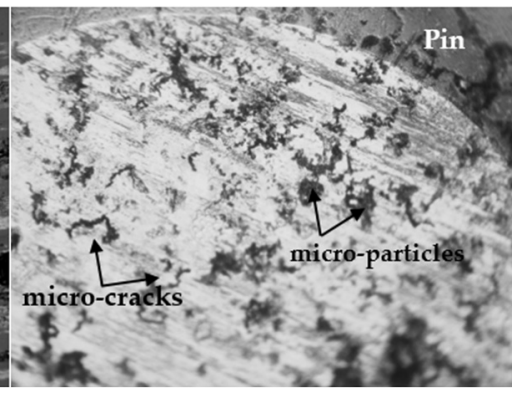

(b)

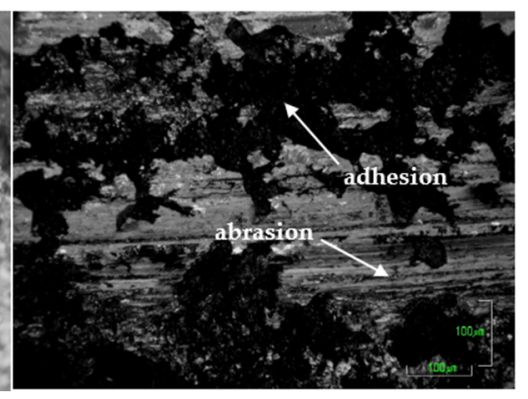

(c)

Figure 6. (a) Wear track of bare soda-lime glass after sliding for $500 \mathrm{~m}$ against stainless steel $(30 \mathrm{~cm} / \mathrm{s}$, $5 \mathrm{~N}, 500 \mathrm{~m})$; (b) Counterface pin after sliding against bare soda-lime glass $(30 \mathrm{~cm} / \mathrm{s}, 5 \mathrm{~N}, 500 \mathrm{~m})$; (c) Wear track of bare soda-lime glass after sliding for $500 \mathrm{~m}$ against stainless steel for intense sliding conditions $(90 \mathrm{~cm} / \mathrm{s}-20 \mathrm{~N})$.

In Figure 7a,b, the wear scars of multilayered polymer-based coatings SH4 20 SIARL and ULTRA 600 are presented, respectively. In both coatings, deformation and tearing phenomena were observed. The asperities of the antagonistic stainless steel surface under the applied load emerge into the surface layers of the polymeric coating. Apparently, localized deformation of the coating took place. With the movement of the counterface, tearing of fibril-like pieces from the polymeric layers occurred, leading to the formation of wear debris [25]. Comparing the two multilayered polymer-based coatings, ULTRA 600 coating exhibited higher wear resistance, possibly due to its fibre-like structure and the 
high number of interphases. Indeed, according to the 3M Company, Ultra 600 coating consists of 40 microlayers, which considerably increase its toughness and tear-resistance in comparison to SH4 20 SIARL coating. Thus, this structure hinders the penetration of stainless steel asperities into the surface of the polymer coating and thus significantly reduces the micro-cutting and micro-ploughing wear phenomena.

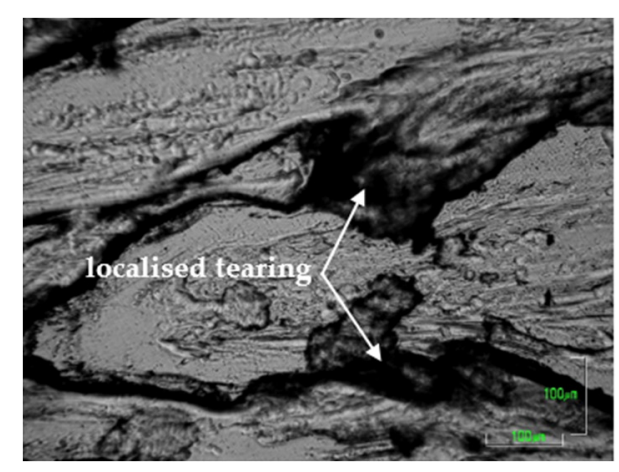

(a)

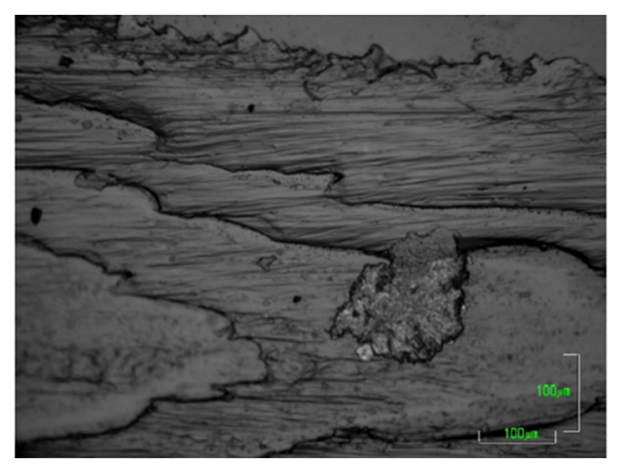

(b)

Figure 7. (a) Wear track of SH4 SIARL coating on soda-lime glass after sliding for $500 \mathrm{~m}$ against stainless steel $(30 \mathrm{~cm} / \mathrm{s}-5 \mathrm{~N})$; (b) Wear track of ULTRA 600 coating on soda-lime glass after sliding for $500 \mathrm{~m}$ against stainless steel $(30 \mathrm{~cm} / \mathrm{s}-5 \mathrm{~N})$.

Another important factor that should be taken into consideration is the adhesion strength of these coatings onto the glass substrate. Figure 8 shows the spectra obtained during the scratch test of the two multilayered polymer coatings on glass. In this figure, two distinctive loads can be discerned, the cohesive load $\left(L_{C}\right)$, which corresponds to the value of load where an acoustic signal is observed for the first time, and the adhesive load $\left(L_{\mathrm{A}}\right)$, which corresponds to the value of load where the highest acoustic signal is observed. For the SH4 20 SIARL coating, the cohesive and adhesive loads were found at 22 and $26 \mathrm{~N}$, respectively. On the other hand, for the ULTRA 600 polymeric coating, the cohesive load $L_{C}$ was observed to be $28 \mathrm{~N}$, whereas the adhesive load $L_{\mathrm{A}}$ was observed at $46 \mathrm{~N}$. In addition, the adhesion strength of these coatings can be correlated to their wear resistance. Indeed, no exfoliation phenomena were observed in the wear track of ULTRA 600 coating, in comparison to the SH4 20 SIARL coating where localized exfoliation occurred at higher loads, as shown in Figure 7a,b, respectively.

The wear track profiles of the multilayered polymer coatings and bare soda-lime glass specimens are presented in Figure 9. The increased roughness of bare soda-lime glass wear track might be due to the presence of microparticles and cracks, which were observed previously. The presence of deformation in the edges of this wear profile was also discernible. These deformation phenomena might be explained by localized heating of the soda-lime glass surface due to abrasion, for temperatures which excided the glass transition temperature. However, other investigators [26] believe that micro-cracks form beneath the surface of the wear scar due to residual stresses, causing a slight deformation of the wear scar profile. The wear scars of the multilayered polymer coatings had lower surface roughness and increased depth, indicative of the deformation and tearing wear mechanism that took place. In addition, a higher roughness was observed within the track of the multilayered polymer coatings when compared to that of the bare glass samples. This is attributed to the different wear mechanisms that occur in these tribosystems. In particular, during the sliding wear of coated samples, the polymeric films are deformed, and localised tearing occurs (Figure 7). This results in a higher surface roughness. On the contrary, during wear of soda-lime glass, the observed mechanisms are mainly adhesion and micro-abrasion (Figure 6), which result in the formation of hard particles. These particles are then removed from the contacting interface due the rotating motion and a smoother track is obtained. 

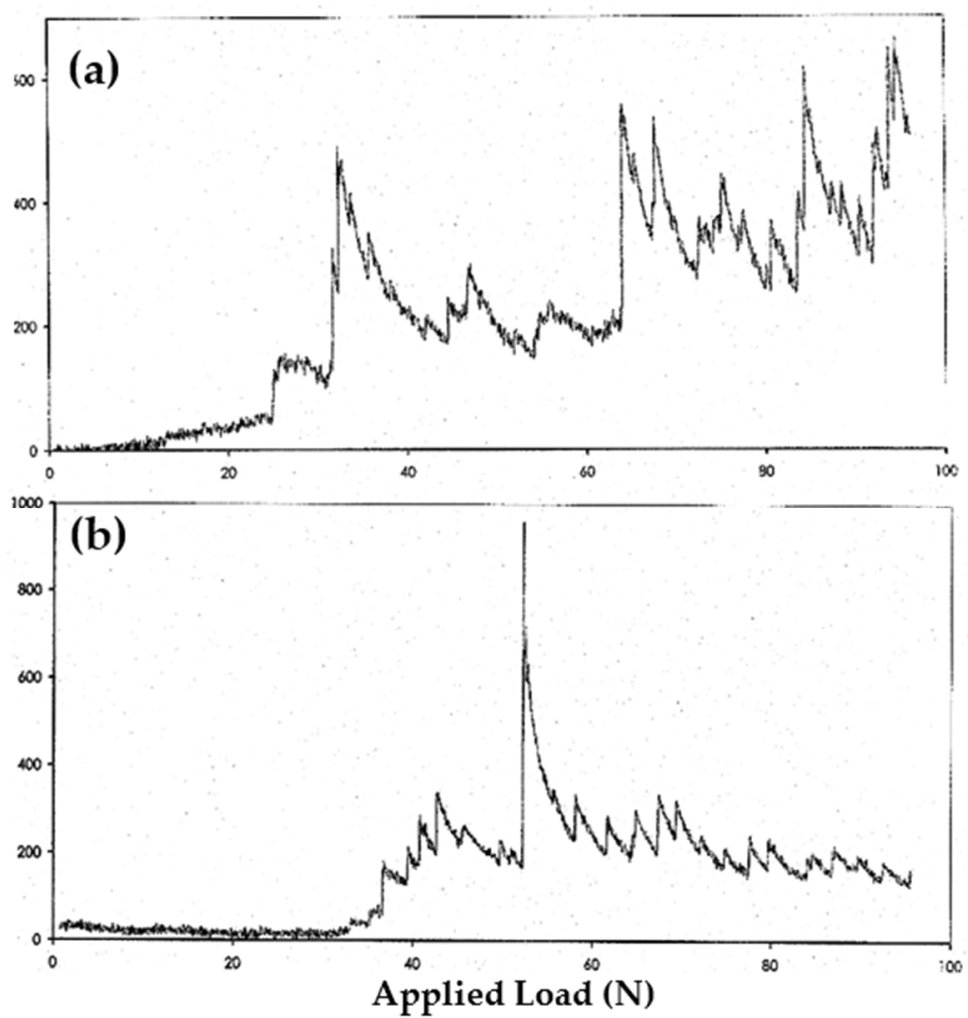

Figure 8. Acoustic emission graphs of (a) SH4 SIARL coated and (b) ULTRA 600 coated soda-lime glass specimens.

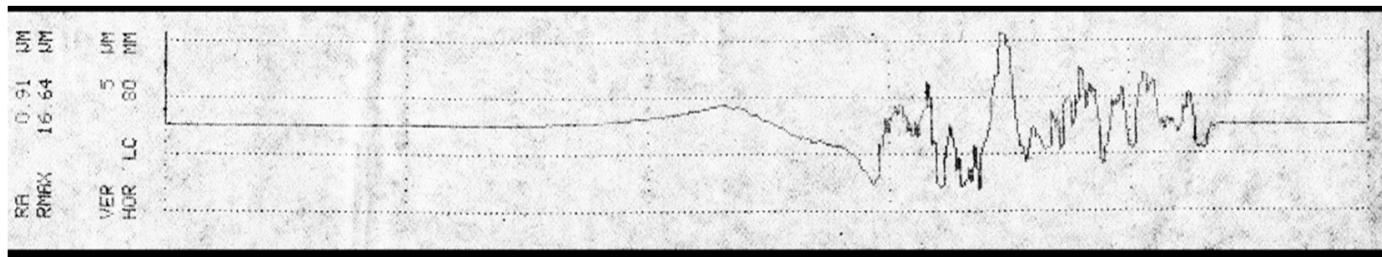

(a)

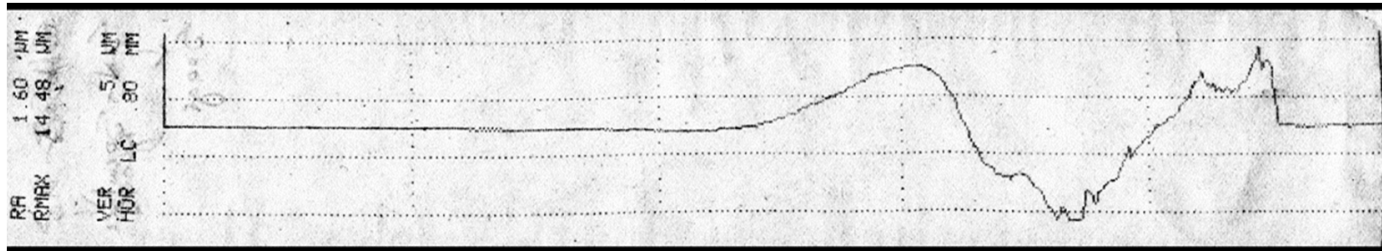

(b)

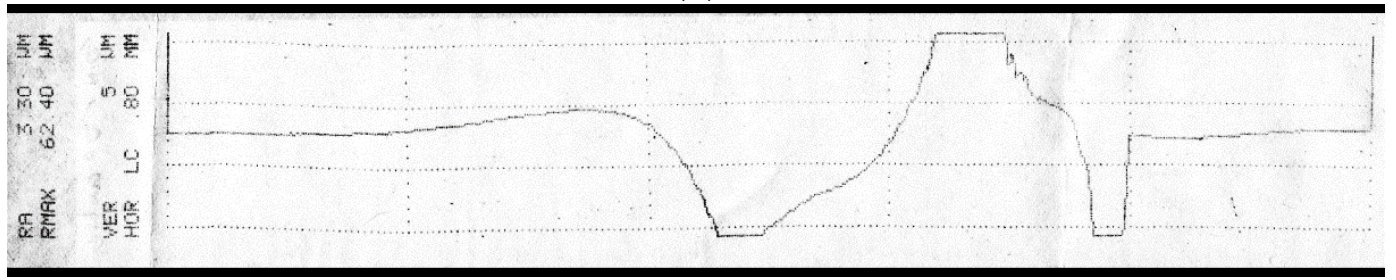

(c)

Figure 9. Wear profile of (a) bare, (b) SH4 SIARL coated and (c) ULTRA 600 coatings on soda-lime glass. 


\section{Conclusions}

From the previous experimental investigation given, the following conclusions can be drawn:

1. The use of nanostructured multilayered polymer-based coatings (safety films) resulted in a significant improvement of the frictional properties of soda-lime glass, when sliding against stainless steel. In addition, the wear loss of coated and bare soda-lime glass was found to strongly depend on the loading conditions.

2. During the dry wear of soda-lime glass against stainless steel counterfaces, the dominant wear mechanisms identified, were adhesive wear, mainly in the initial steps, followed by micro-cracking and abrasion, whereas, during the dry wear of the multilayered polymer coatings against stainless steel counterfaces, deformation and tearing of the polymeric layers took place.

3. Changes in the sliding speed did not have a considerable effect on the frictional behaviour of the examined tribosystems.

4. ULTRA 600 coatings have improved wear resistance and adhesion strength when compared to SH4 20 SIARL, due to their fibre-like structure and comparatively high number of interphases.

Acknowledgments: The authors would like to thank the 3M Company in Greece for providing the selected safety films.

Author Contributions: C.N.P. conceived and designed the experiments; C.N.P. and E.P.G. wrote the paper; C.N.P. and K.I.G. analyzed the data; G.S.T. and E.P.G. performed the experiments.

Conflicts of Interest: The authors declare no conflict of interest.

\section{References}

1. Ferreira, J.G.; Branco, F.A. Structural application of GRC in telecommunication towers. Constr. Build. Mater. 2007, 21, 19-28. [CrossRef]

2. Schüler, A.; Dutta, D.; Chambier, E.; Roecker, C.; Temmerman, G.; Oelhafen, P.; Scartezzini, J.L. Sol-gel deposition and optical characterization of multilayered $\mathrm{SiO}_{2} / \mathrm{Ti}_{1}-{ }_{x} \mathrm{Si}_{x} \mathrm{O}_{2}$ coatings on solar collector glasses. Sol. Energy Mater. Sol. Cells 2006, 90, 2894-2907. [CrossRef]

3. Kawakame, M.; Bressan, J.D. Study of wear in self-lubricating composites for application in seals of electric motors. J. Mater. Process. Technol. 2006, 179, 74-80. [CrossRef]

4. Zhukov, A. Glass-coated magnetic microwires for technical applications. J. Magn. Magn. Mater. 2002, 242-245, 216-223. [CrossRef]

5. Mohajerani, A.; Spelt, J.K. Erosive wear of borosilicate glass edges by unidirectional low velocity impact of steel balls. Wear 2010, 269, 900-910. [CrossRef]

6. Shipway, P.H.; Hutchings, I.M. The role of particle properties in the erosion of brittle materials. Wear 1996, 193, 105-113. [CrossRef]

7. Gong, J.; Chen, Y.; Li, C. Statistical analysis of fracture toughness of soda-lime glass determined by indentation. J. Non-Cryst. Solids 2001, 279, 219-223. [CrossRef]

8. Panagopoulos, C.N.; Georgarakis, C.G. Bending Behaviour of Heat Treated Soda-Lime Glass. In Proceedings of the 1st Balkan Conference on Glass Science \& Technology, Volos, Greece, 9-10 October 2000.

9. Panagopoulos, C.N.; Georgarakis, C.G. The Abrasive Wear of Soda-Lime Glass. In Proceedings of the 2nd Balkan Conference on Glass Science \& Technology, Varna, Boulgaria, 24-28 September 2002.

10. Panagopoulos, C.N.; Fasoula, E.; Michaelides, A. The abrasive wear of borosilicate glass. J. Mater. Sci. 1994, 29, 773-777. [CrossRef]

11. Shipway, P.H. The role of test conditions on the microabrasive wear behaviour of soda-lime glass. Wear 1999, 233-235, 191-199. [CrossRef]

12. Shipway, P.H.; Hodge, C.J.B. Microabrasion of glass-The critical role of ridge formation. Wear 2000, 237, 90-97. [CrossRef]

13. He, H.; Qian, L.; Pantano, C.G.; Kim, S.H. Effects of humidity and counter-surface on tribochemical wear of soda-lime-silica glass. Wear 2016, 342-343, 100-106. [CrossRef] 
14. Bousbaa, C.; Madjoubi, A.; Hamidouche, M.; Bouaouadja, N. Effect of annealing and chemical strengthening on soda lime glass erosion wear by sand blasting. J. Eur. Ceram. Soc. 2003, 23, 331-343. [CrossRef]

15. Shipway, P.H.; Hogg, J.J. Wear of bulk ceramics in micro-scale abrasion-The role of abrasive shape and hardness and its relevance to testing of ceramic coatings. Wear 2007, 263, 887-895. [CrossRef]

16. Wiederhorn, S.M.; Roberts, D.E. Influence of normal alcohols on the abrasive wear of glass. Wear 1975, 32, 51-72. [CrossRef]

17. Panagopoulos, C.N. Polymers and Composite Materials; NTUA Publishing: Athens, Greece, 1992; p. 56.

18. Myshkin, N.K.; Petrokovets, M.I.; Kovalev, A.V. Tribology of polymers: Adhesion, friction, wear, and mass-transfer. Tribol. Int. 2005, 38, 910-921. [CrossRef]

19. Cullity, B.D. Elements of X-ray Diffraction, 1st ed.; Addison-Wesley Publishing Company: Boston, MA, USA, 1959; p. 259.

20. Bowden, P.B.; Jukes, J.A. The plastic flow of isotropic polymers. J. Mater. Sci. 1972, 7, 52-63. [CrossRef]

21. Rabinowicz, E. Friction and Wear of Materials, 2nd ed.; Wiley Interscience Publication: New York, NY, USA, 1995; p. 194.

22. Hutchings, I.M. Tribology: Friction and Wear of Engineering Materials, 1st ed.; Edward Arnold, Elsevier: London, UK, 1992; pp. 82-86.

23. Friedrich, K.; Karger-Kocsis, J.; Lu, Z. Effects of steel counterface roughness and temperature on the friction and wear of $\mathrm{PE}(\mathrm{E}) \mathrm{K}$ composites under dry sliding conditions. Wear 1991, 148, 235-247. [CrossRef]

24. Corengia, P.; Walther, F.; Ybarra, G.; Sommadossi, S.; Corbari, R.; Broitman, E. Friction and rolling-sliding wear of DC-pulsed plasma nitrided AISI 410 martensitic stainless steel. Wear 2006, 260, 479-485. [CrossRef]

25. Zhang, M.Q.; Friedrich, K.; Batzar, K.; Thomas, P. Abrasive wear mechanisms of fluoropolymer-based composite coatings on aluminium substrates. Wear 1996, 200, 122-136. [CrossRef]

26. Li, K.; Shapiro, Y.; Li, C.M. Scratch test of soda-lime glass. Acta Mater. 1998, 46, 5569-5578. [CrossRef]

(C) 2016 by the authors; licensee MDPI, Basel, Switzerland. This article is an open access article distributed under the terms and conditions of the Creative Commons Attribution (CC-BY) license (http://creativecommons.org/licenses/by/4.0/). 